\title{
Short days induce premature reproductive maturation in juvenile starlings, Sturnus vulgaris*
}

\author{
T. D. Williams $\dagger$, A. Dawson, T. J. Nicholls $\ddagger$ and A. R. Goldsmith $\ddagger$ \\ NERC, Institute of Terrestrial Ecology, Monks Wood Experimental Station, Abbots Ripton, \\ Huntingdon, Cambs PE17 2LS, and $\ddagger$ AFRC Research Group on Photoperiodism \& Reproduction, \\ Department of Zoology, University of Bristol, Bristol BS8 IUG, U.K.
}

\begin{abstract}
Summary. Castration of juvenile and photorefractory adult starlings caused no immediate increase in circulating concentrations of LH. In castrated juveniles and adults exposed to natural changes in daylength, plasma LH increased between mid-October and mid-November, although the increase was more rapid in adults. In castrated photorefractory adults, plasma $\mathrm{LH}$ increased 3-5 weeks after transfer to artificial short days (8L:16D). In castrated juvenile starlings plasma LH increased 4-6 weeks after transfer to $8 \mathrm{~L}: 16 \mathrm{D}$, irrespective of the age of the birds. Birds as young as 17 weeks had high $\mathrm{LH}$ concentrations. These results suggest that the reproductive system of juvenile starlings is in the same state as that of photorefractory adults, and therefore that activation of the hypothalamo-pituitary axis for the first time in juveniles is analagous to the termination of photorefractoriness in adults.
\end{abstract}

\section{Introduction}

Seasonal reproduction in most temperate-zone avian species is terminated by spontaneous gonadal regression at the onset of a 'photorefractory' state (Bissonette \& Wadlund, 1932; Riley, 1936; Burger, 1947). Photorefractory birds are insensitive to further stimulation by long daylengths and this prevents breeding attempts being made when ecological factors, particularly food supply, are unfavourable for successfully rearing young. Refractoriness is maintained during the summer, while the bird experiences long daylengths, and is terminated during the short days of autumn (Lofts \& Murton, 1968). Exposure of birds to artificial short daylengths can terminate refractoriness prematurely (Burger, 1947; Wolfson, 1952; Steel et al., 1975). Short days appear to 'switch on' the reproductive system at the hypothalamic level (Nicholls et al., 1984; Dawson et al., 1985, 1986).

Juvenile birds of most temperate-zone species are also insensitive to the stimulatory effects of long daylengths, from at least a few weeks after hatching until the following autumn (Farner et al., 1983). The mechanism underlying this phenomenon in young birds is not known although it has been suggested that juveniles may display a form of photorefractoriness which is physiologically similar or identical to that of adult photorefractoriness (Farner et al., 1983; Sharp, 1984). If this is the case, it can be predicted that exposure of juvenile birds to short days should cause a premature 'switch on' of the reproductive system and induce precocious reproductive development.

The work described here investigated the timing of the development of photosensitivity under natural daylengths in juvenile starlings, Sturnus vulgaris, and the effect of artificial short days on the onset of photosensitivity. Castrated male birds were used in these experiments because in

* Reprint requests to Dr A. Dawson.

†Present address: British Antarctic Survey, High Cross, Madingley, Cambridge CB3 0ET, UK. 
gonadectomized adult starlings, plasma luteinizing hormone (LH) concentrations are maximal in photosensitive birds, even in short daylengths, and basal in photorefractory birds (Goldsmith \& Nicholls, 1984). Termination of refractoriness and the recovery of photosensitivity in castrated adult starlings is signalled by a rapid increase in plasma LH (Dawson \& Goldsmith, 1984).

\section{Materials and Methods}

Juvenile starlings (Sturnus vulgaris) are easily distinguished from adults by their light brown feathers, which are replaced by dark adult feathers during the autumn moult. Adult and juvenile starlings were captured at a sewage works in Cambridgeshire $\left(52^{\circ} \mathrm{N}\right)$ before this moult. Since breeding in starlings is highly synchronous, and only one brood is normally raised, the age of juveniles can be calculated with reference to the mean hatching date for that year.

All birds were provided with food (chick starter crumbs: Whetstones, St Ives, Cambs) and water ad libitum. Birds kept under natural daylengths were held in unheated outdoor aviaries $(4 \times 2 \times 2 \mathrm{~m})$. Those under artificial daylengths were kept in aluminium cages $(0.6 \times 0.4 \times 0.4 \mathrm{~m})$ with $3-5$ birds per cage. The cages were in light proof rooms illuminated by $80-\mathrm{W}$ fluorescent tubes.

All birds were anaesthetized with an i.m. injection of 40-70 $\mu \mathrm{l} 5 \%$ metomidate hydrochloride (Hypnodil; Veterinary Drug Co. PLC, Dunnington, York) and an incision was made between the last pair of ribs. Birds were sexed by examination of the gonads. If male, the testes were removed by using fine curved forceps. Blood samples were collected from the brachial vein before castration and at frequent intervals during the following experiments. Blood was centrifuged at $1800 \mathrm{~g}$ for $10 \mathrm{~min}$ and plasma was stored at $-20^{\circ} \mathrm{C}$ until assayed. There were 4 experimental groups.

In Group 1, 5 juvenile male and 8 adult males, caught in July 1984, were held in outdoor aviaries. They were castrated on 24 July and blood samples were collected frequently until 24 December.

In Group 2, 7 adult males, caught in July 1984, were held in outdoor aviaries until June 1985. They were therefore at least 2 years old, had completed a gonadal cycle in captivity, and were photorefractory. They were castrated on 26 June and transferred to short days, $8 \mathrm{~h}$ light:16 h darkness per day (8L:16D) for 10 weeks. In all groups, lights were switched on at $08: 00 \mathrm{~h}$.

In Group 3, juvenile males were caught in June 1984 and kept in outdoor aviaries. On 25 July (age 11 weeks) 4 were castrated and transferred to 8L:16D for 22 weeks. On 20 August (age 15 weeks) 6 more were castrated and transferred to $8 \mathrm{~L}: 16 \mathrm{D}$ for 18 weeks.

In Group 4, 6 juvenile males, caught in June 1984, were castrated on 22 June (age 7 weeks), kept on 18L:6D for 18 weeks, and then transferred to $8 \mathrm{~L}: 16 \mathrm{D}$ for 10 weeks.

In another experiment, 10 male nestling starlings were taken from nest boxes at 8 days of age, castrated, and kept in 18L:6D. They were hand fed on maggots until capable of feeding independently on chick crumbs. At 7 weeks of age, 5 were transferred to $8 \mathrm{~L}: 16 \mathrm{D}$ and the remaining 5 were kept in $18 \mathrm{~L}: 6 \mathrm{D}$.

All plasma samples were assayed for LH using an homologous chicken LH radioimmunoassay (Follett $e t$ al., 1972,1975 ) as previously described for starlings (Dawson \& Goldsmith, 1982). The sensitivity of the assay was $0.1 \mu \mathrm{g} / \mathrm{l}$. Inter- and intra-assay variation was $12.2 \%(n=7)$ and $7 \cdot 7 \%(n=8)$ respectively. Results were assessed by analysis of variance with Newman-Keuls tests to determine the significance of differences between mean concentrations (Snedecor \& Cochran, 1980).

\section{Results}

Castrated juvenile and adult starlings (Group 1), kept on natural daylengths between July and December showed no increase in plasma $\mathrm{LH}$ concentration at the time of castration (Fig. 1). Plasma LH remained low $(<0.2 \mu \mathrm{g} / \mathrm{l})$ in both groups until mid-October, then increased in juveniles and adults between mid-October and mid-November $(P<0.05)$. In adults $\mathrm{LH}$ reached a peak at $1.73 \mu \mathrm{g} / \mathrm{l}$ in mid-November and then remained high. In juveniles LH increased more gradually reaching a peak of $1.18 \mu \mathrm{g} / 1$ in mid-December. Plasma $\mathrm{LH}$ concentrations were significantly higher in adult birds in mid- and late November $(P<0.05)$.

In photorefractory adults (Group 2), plasma LH concentrations remained low after castration and for 3 weeks after transfer to short days (Fig. 2a). LH then increased significantly $(P<0.01)$ from $0.08 \mu \mathrm{g} / \mathrm{l}$ after 3 weeks to $1.62 \mu \mathrm{g} / \mathrm{l}$ after 5 weeks of short days, and remained high until the end of the experiment.

Changes in plasma LH concentrations were very similar in castrated juveniles transferred to short days at 11 and 15 weeks of age (Group 3). Castration caused no immediate increase in LH, and values remained low $(<0.2 \mu \mathrm{g} / \mathrm{l})$ for 4 weeks after transfer to short days. There was then a 


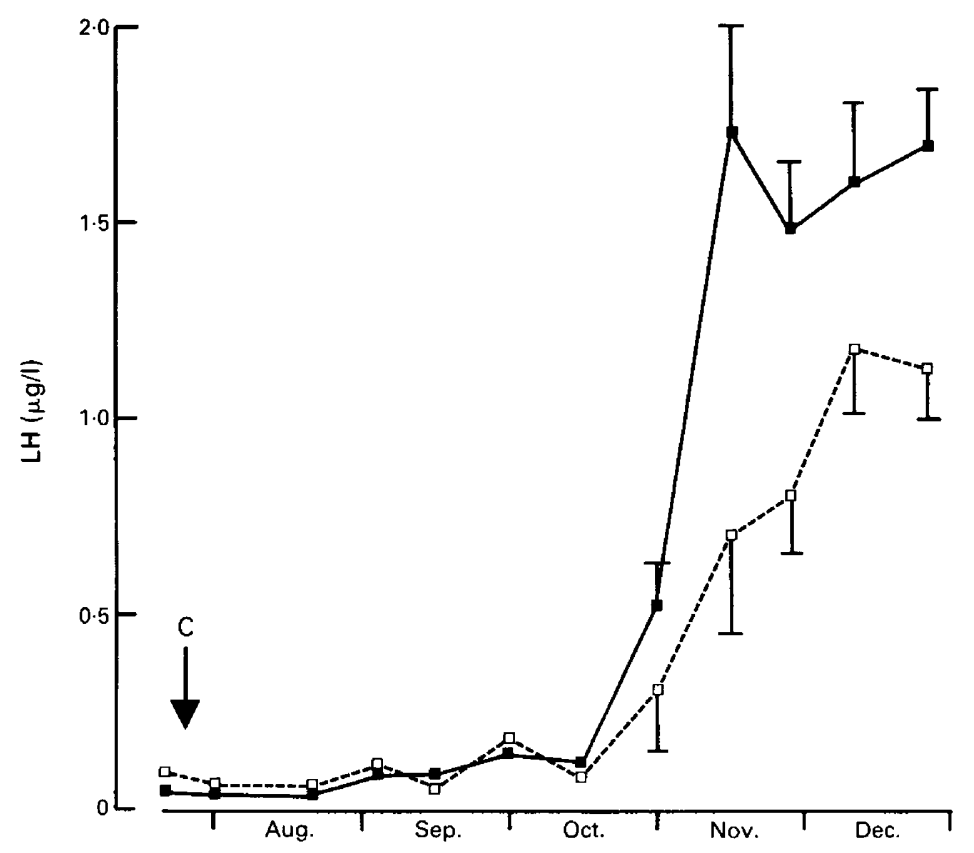

Fig 1. Changes in plasma LH concentrations in castrated adult starlings $(\boldsymbol{\square}-\mathbf{E}, \mathbf{N}=8)$ and castrated juvenile starlings $(\square---\square, N=5$ ) held in outdoor aviaries in Cambridgeshire, U.K. $\left(52^{\circ} \mathrm{N}\right)$. Each point represents mean \pm s.e.m. Where errors are not shown, they are within the symbol. The arrow $(\mathrm{C})$ indicates when birds were castrated.

significant increase $(P<0.01)$ in LH concentrations by 6 weeks of short days in both groups (Figs $2 \mathrm{~b} \& 2 \mathrm{c})$ and values remained high until the end of the experiment.

Castrated juveniles kept in 18L:6D for 18 weeks (Group 4) had low plasma LH concentrations $(<0.2 \mu \mathrm{g} /$ l; Fig. $2 \mathrm{~d})$. Transfer to short days caused a significant $(P<0.01)$ increase in LH to $1 \cdot 17 \mu \mathrm{g} / \mathrm{l}$ after 6 weeks.

In castrated nestlings transferred to short days at 7 weeks of age, plasma LH remained low for 4 weeks (Fig. 3). Concentrations then increased significantly to $0.55 \mu \mathrm{g} / \mathrm{l}$ after 6 weeks of short days $(P<0.01)$ and continued to increase until 10 weeks. LH concentrations in birds maintained in long days for 10 weeks remained $<0: 2 \mu \mathrm{g} / 1$.

\section{Discussion}

Castrated photorefractory adult starlings and castrated juvenile starlings, held under natural daylengths, showed a marked increase in circulating concentrations of $\mathrm{LH}$ between October and November. Dawson \& Goldsmith (1984) reported a similar increase in plasma LH concentrations at this time of year in gonadectomized adult male and female starlings. This rise in LH indicates the end of photorefractoriness and a return to photosensitivity in adult birds (Goldsmith \& Nicholls, 1984). Presumably the increase in LH in juveniles similarly represents the development of photosensitivity and the activation of the reproductive system (Dawson et al., 1986). Starlings are therefore similar to many other temperate-zone species in that adults and juveniles become photosensitive at the same time under natural daylengths (Miller, 1948; Wolfson, 1952; Farner \& Mewaldt, 1955).

In the photosensitive non-photostimulated adult starling, removal of gonadal steroid inhibition by gonadectomy allows the neuroendocrine system to function at its maximal rate (Goldsmith $\&$ 

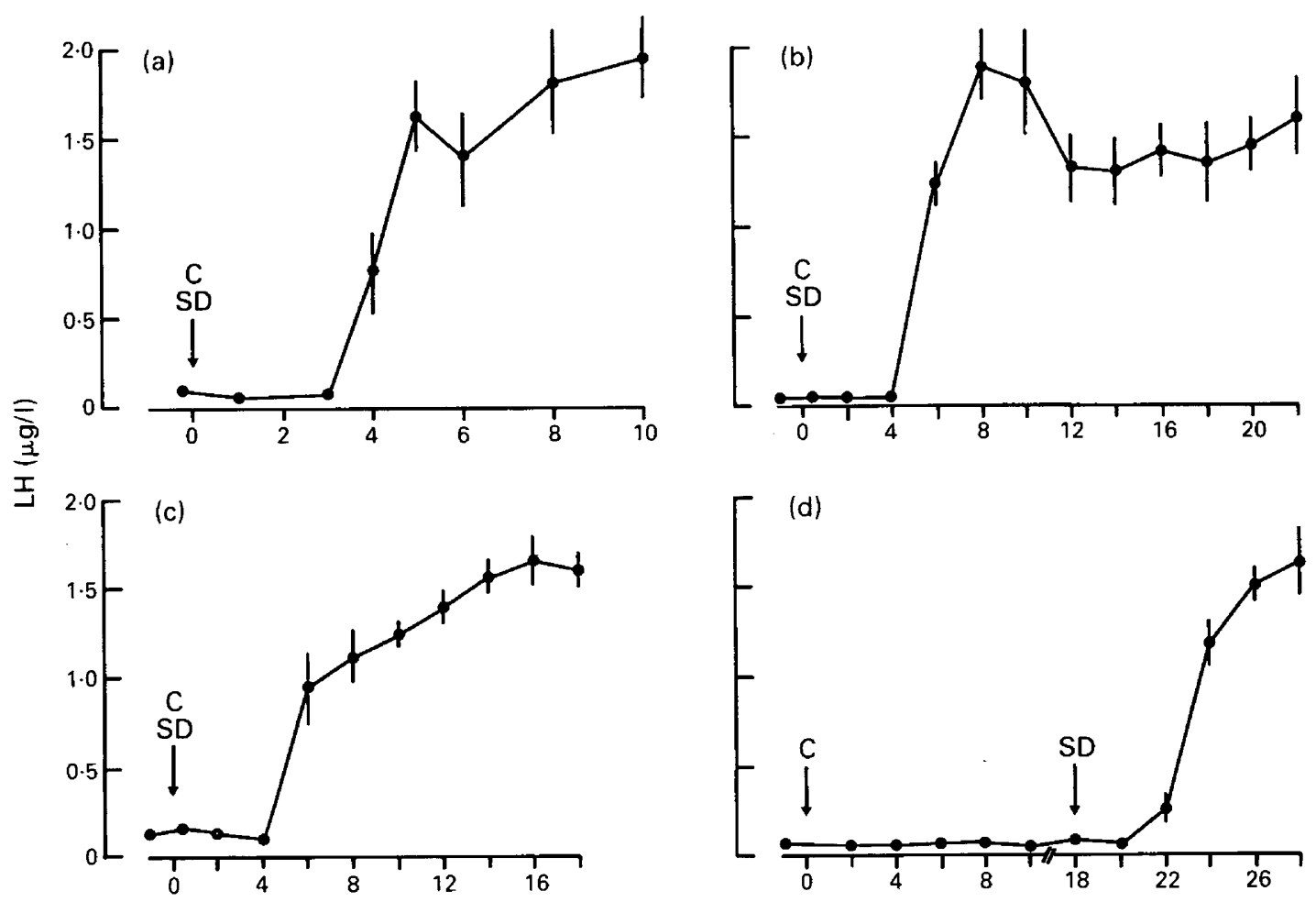

Weeks

Fig. 2. Plasma $\mathrm{LH}$ concentrations in (a) adult photorefractory starlings $(\mathrm{N}=7)$ castrated and transferred from natural daylengths to $8 \mathrm{~L}: 16 \mathrm{D}$ on 26 June (Week 0), (b) juvenile starlings $(\mathrm{N}=4)$ castrated and transferred from natural daylengths to $8 \mathrm{~L}: 16 \mathrm{D}$ on 25 July (Week 0 ), (c) juvenile starlings $(\mathrm{N}=6)$ castrated and transferred from natural daylengths to $8 \mathrm{~L}: 16 \mathrm{D}$ on 20 August (Week 0), (d) juvenile starlings $(N=6$ ) castrated and transferred from natural daylengths to $18 \mathrm{~L}: 6 \mathrm{D}$ on 22 June (Week 0 ) and then transferred to $8 \mathrm{~L}: 16 \mathrm{D}$ after 18 weeks. All points represent means \pm s.e.m. The arrows indicate time of castration (C) and transfer to short days (SD).

Nicholls, 1984). The increase in plasma LH during the development of photosensitivity in natural daylengths was less marked in juvenile than in adult starlings, which suggests that the juvenile hypothalamo-pituitary axis is not able to function at a maximal rate even though the birds become photosensitive. This would be consistent with the suggestion that there is a gradual maturation of the photoperiodic response system in young birds (Thapliyal \& Chatterii, 1965; Farner et al., 1983). However, secretion of LH to its maximum values (for the species) was induced in juvenile starlings as young as 17 weeks of age under experimental conditions $8 \mathrm{~L}: 16 \mathrm{D}, 6$ weeks in advance of the development of photosensitivity under natural daylengths. The juvenile neuroendocrine system clearly has the potential for maximum secretion of gonadotrophins many weeks before such concentrations are observed under natural daylengths. The difference between the two age groups may instead reflect different rates of recovery of complete photosensitivity, on the same short daylength. Under experimental conditions maximum concentrations of plasma $\mathrm{LH}$ occur in juvenile birds after development of photosensitivity in very short daylengths. Development of photosensitivity under natural daylengths occurs in daylengths which, although 'short', are considerably longer, about $11 \mathrm{~L}: 14 \mathrm{D}$. It is possible that $8 \mathrm{~L}: 16 \mathrm{D}$ allows a rapid, complete recovery of photosensitivity 


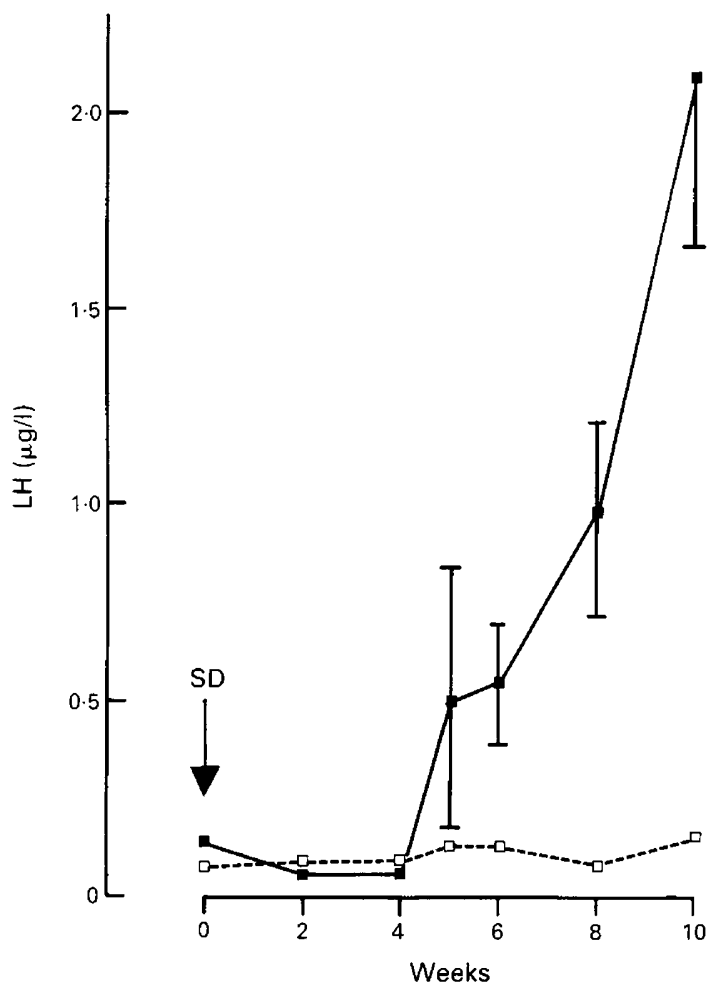

Fig. 3. Plasma LH concentrations in castrated juvenile starlings after transfer at 7 weeks of age (Week 0) from 18L:6D to 8L:16D ( $\square-\mathrm{N}=5$ ) or kept in 18L:6D $(\square--\square, \mathrm{N}=5$ ). These birds had been castrated when 8 days old and then kept in 18L:6D. Each point represents mean \pm s.e.m. Where errors are not shown, they are within the symbol.

whereas gradually decreasing and longer 'short' days cause a more gradual development of photosensitivity (see Farner \& Follett, 1966; Hamner, 1968). There is some evidence in the canary that the rate of recovery of photosensitivity is proportional to the length of the short day to which the bird has been exposed (Nicholls \& Storey, 1977). With this hypothesis it is necessary to explain why adult birds do appear to recover complete photosensitivity on daylengths of $11 \mathrm{~L}$ under natural conditions. In Japanese quail the bird's interpretation of daylength is affected by its previous photoperiodic 'history' (Robinson \& Follett, 1982), and, in starlings too, the photoperiodic response varies with age and, independently, with previous photoperiodic experience (T. D. Williams, unpublished results). It is therefore possible that in adult starlings the photoperiodic response has altered such that they can recover complete photosensitivity under long 'short' daylengths, i.e. a daylength not perceived as short earlier in the year.

Castration of photorefractory adult starlings caused no increase in plasma LH concentrations confirming that gonadal steroids are not involved in maintaining low LH concentration (Goldsmith $\&$ Nicholls, 1984). Transfer of refractory adults to short days caused a marked increase in plasma LH after 3-5 weeks, indicating a return to photosensitivity. Peak plasma LH concentrations occurred after 8-10 weeks of short days and these were typical of the maximum levels normally recorded for the starling (Dawson \& Goldsmith, 1984; Goldsmith \& Nicholls, 1984). Other studies have similarly shown a marked increase in plasma $\mathrm{LH}$ in castrated photorefractory starlings after 3-4 (Goldsmith \& Nicholls, 1984) and 4-6 (A. Dawson, unpublished results) weeks of short days. Removal of gonads from juvenile starlings at 7,11 or 15 weeks of age caused no increase in plasma 
LH concentrations. Low LH concentrations in juveniles are not therefore caused by the negative feedback effect of gonadal steroids. Long daylengths do not stimulate $\mathrm{LH}$ release even in the absence of gonadal steroids. Subsequent transfer of castrated juveniles to short days caused a marked increase in plasma $\mathrm{LH}$ after 4-6 weeks in all birds regardless of age. High plasma LH concentrations $(>1.5 \mu \mathrm{g} / \mathrm{l})$ occurred in all juvenile birds after $8-10$ weeks of short days. The response of castrated juveniles to short days is therefore almost identical to that of photorefractory adults. In juvenile starlings the development of photosensitivity is not controlled by an agedependent maturational process but is profoundly influenced by the photoperiod which the bird experiences. Short days can 'switch on' the reproductive system prematurely, initiating gonadotrophin secretion, in birds as young as 12 weeks old. It therefore appears that the juvenile reproductive system is mature at an early age (less than 7 weeks old) but is 'switched off', i.e. the bird is in a photorefractory state. Short days are required to switch on the system before the bird can respond to long daylengths. The similarity of the response to short days in juveniles and adult starlings suggests that there may be a common physiological mechanism underlying the termination of the refractory state in adults, and the activation of the hypothalamo-pituitary axis for the first time in juveniles.

In the experiments reported here, the spontaneous increase in plasma $\mathrm{LH}$ concentrations in castrated birds, at some time after transfer to short daylengths, was assumed to signal the acquisition of photosensitivity. Some degree of caution should be exercised in interpreting these results and when comparing them with results of other workers using different species. Many earlier experiments used the increase in gonadal size after transfer to long daylengths to determine when photosensitivity is acquired. This is likely to reflect changes in plasma FSH concentrations more than LH, and the responses of these two hormones may not be identical. In previous experiments with adult starlings we have found that changes in plasma FSH are qualitatively similar to those of LH. We have not yet shown this for juveniles, mainly because of a practical difficulty; the antiserum used for measuring FSH is in very short supply. A second reason for caution is that starlings appear slightly unusual in that castration of photosensitive birds held in short daylengths causes plasma LH concentrations to increase to maximal values. Transfer to long daylengths causes no further increase. However, this is probably one extreme of a range of responses. In some species, e.g. white-crowned sparrows, there is very little increase in LH after castration in short daylengths, but a marked increase when castrated birds are transferred to long daylengths (Wingfield et al., 1980). Tree sparrows (Wilson \& Follett, 1977) and canaries (Storey et al., 1980) show an intermediate response. It is because starlings show this extreme response that they are useful for this type of experiment.

\section{T. D. W. was in receipt of an NERC CASE studentship.}

\section{References}

Bissonette, T.H. \& Wadlund, A.P. (1932) Duration of testis activity of Sturnus vulgaris in relation to type of illumination. J. exp. Biol. 9, 339-350.

Burger, J.W. (1947) On the relation of daylength to the phase of testicular involution and inactivity of the spermatogenetic cycle of the starling. J. exp. Zool. 105, 259-267.

Dawson, A. \& Goldsmith, A.R. (1982) Prolactin and gonadotrophin secretion in wild starlings (Sturnus vulgaris) during the annual cycle and in relation to nesting, incubation and rearing young. Gen. comp. Endocr. 48, 213-221.
Dawson, A. \& Goldsmith, A.R. (1984) Effects of gonadectomy on seasonal changes in plasma LH and prolactin concentrations in male and female starlings (Sturnus vulgaris). J. Endocr. 100, 213-218.

Dawson, A., Follett, B.K., Goldsmith, A.R. \& Nicholls, T.J. (1985) Hypothalamic gonadotrophin-releasing hormone and pituitary and plasma FSH and prolactin during photostimulation and photorefractoriness in intact and thyroidectomized starlings (Sturnus vulgaris). J. Endocr. 105, 71-77.

Dawson, A., Goldsmith, A.R., Nicholls, T.J. \& Follett, B.K. (1986) Endocrine changes associated with the 
termination of photorefractoriness by short daylengths and thyroidectomy in starlings (Sturnus vulgaris). J. Endocr. 110, 73-79.

Farner, D.S. \& Mewaldt, L.R. (1955) Natural termination of the refractory period in white-crowned sparrows. Condor 57, 112-116.

Farner, D.S. \& Follett, B.K. (1966) Light and other environmental factors affecting avian reproduction. J. Anim. Sci. 25, 90-118.

Farner, D.S., Donham, R.S., Matt, K.S., Mattocks, P.W., Moore, M.C. \& Wingfield, J.C. (1983) The nature of photorefractoriness. In Avian Endocrinology: Environmental and Ecological Perspectives, pp. 14-166. Eds S. Mikami, K. Homma \& M. Wada. Japan Sci. Soc. Press, Tokyo.

Follett, B.K., Scanes, C.G. \& Cunningham, F.J. (1972) A radioimmunoassay for avian luteinizing hormone. $J$. Endocr. 52, $359-378$.

Follett, B.K., Farner, D.S. \& Mattocks, P.W. (1975) Luteinizing hormone in the plasma of white crowned sparrows (Zonotrichia leucophrys gambelit) during artificial photostimulation. Gen. comp. Endocr. 26, 126-1 34.

Goldsmith, A.R. \& Nicholls, T.J. (1984) Prolactin is associated with the development of photorefractoriness in intact, castrated and testosterone-implanted starlings. Gen. comp. Endocr. 54, 247-255.

Hamner, W.M. (1968) The photorefractory period of the house finch. Ecology 49, 211-227.

Lofts, B. \& Murton, R.K. (1968) Photoperiodic and physiological adaptations regulating avian breeding cycles and their ecological significance. J. Zool., Lond. 155, 327-394.

Miller, A.H. (1948) The refractory period in lightinduced reproductive development of goldencrowned sparrows. J. exp. Zool. 109, 1-11.

Nicholls, T.J. \& Storey, C.R. (1977) The effect of duration of the daily photoperiod on recovery of photosensitivity in photorefractory canaries (Serinus canarius). Gen. comp. Endocr. 31, 72-74.

Nicholls, T.J., Goldsmith, A.R. \& Dawson, A. (1984) Photorefractoriness in European starlings: associated hypothalamic changes and the involvement of thyroid hormones and prolactin. J. exp. Zool. 232, $567-572$.
Riley, G. (1936) Light regulation of sexual activity in the male sparrow (Passer domesticus). Proc. Soc. exp. Biol. Med. 34, 331-332.

Robinson, J.E. \& Follett, B.K. (1982) Photoperiodism in the Japanese quail: the termination of seasonal breeding by photorefractoriness. Proc. R. Soc. B 215, 95-116.

Sharp, P.J. (1984) Seasonal breeding and sexual maturation. In Reproductive Biology of Poultry pp. 203-218. Eds F. J. Cunningham. P. E. Lake \& D. Hewitt. Longman group; British Poultry Science Ltd, Harlow.

Snedecor, G.W. \& Cochran, W.G. (1980) Statistical Methods, 6th edn. Iowa State University Press, Ames.

Steel, E., Follett, B.K. \& Hinde, R.A. (1975) The role of short days in the termination of photorefractoriness in female canaries (Serinus canarius). J. Endocr. 64, $451-464$.

Storey, C.R., Nicholls, T.J. \& Follett, B.K. (1980) Castration accelerates the onset of photorefractoriness in the canary (Serinus serinus). Gen. comp. Endocr. 42, 315-319.

Thapliyal, J.P. \& Chatterji, S. (1965) Juvenile phase in weaver finch (Ploceus phillipinus). J. exp. Zool. 159, 203-208.

Wilson, F.E. \& Follett, B.K. (1977) Testicular inhibition of gonadotrophin secretion in photosensitive tree sparrows (Spizella arborea) exposed to a winter-like daylength. Gen. com. Endocr. 32, 440 445.

Wingfield, J.C., Follett, B.K., Matt, K.S. \& Farner, D.S. (1980) Effect of daylength on plasma FSH and LH in castrated and intact white-crowned sparrows. Gen. comp. Endocr. 42, 464-470.

Wolfson, A. (1952) The occurrence and regulation of the refractory period in the gonadal and fat cycles of the junco. J. exp. Zool. 121, 311-325.

Received 29 October 1986 